\title{
USO DE CLAE NO CONTROLE DE QUALIDADE EM PRODUTOS COMERCIAIS DE NIM: REPRODUTIBILIDADE DA AÇÃO INSETICIDA
}

\author{
Moacir Rossi Forim*, Andréia Pereira Matos, Maria Fátima das Graças Fernandes da Silva, Quézia Bezerra Cass, Paulo \\ Cezar Vieira e João Batista Fernandes \\ Departamento de Química, Universidade Federal de São Carlos, CP 676, 13565-905 São Carlos - SP, Brasil
}

Recebido em 12/8/09; aceito em 6/1/10; publicado na web em 3/5/10

\begin{abstract}
THE USE OF HPLC IN THE CONTROL OF NEEM COMMERCIAL PRODUCTS QUALITY: REPRODUCTION OF THE INSECTICIDE ACTION. The Neem tree, Azadirachta indica, provides many useful compounds that are used as pesticides. However, the efficiency in field of products like neem oil can be committed because they have not been observed reproductive content of secondary metabolic like azadirachtin. Based on reverse-phase high-performance liquid chromatography (HPLC) a new method was developed to permit the rapid quantitative analysis of azadirachtin from seeds, extracts and oil of Neem. In the present study it was evaluated the azadirachtin quantitative variation among various Neem's extracts and seeds showing the importance of quality control for reproduction of the insecticide efficiency, using S. frugiperda as target insect.
\end{abstract}

Keywords: Azadirachta indica; insecticide action; S. frugiperda.

\section{INTRODUÇÃO}

O sucesso das modernas práticas agrícolas em geral depende da descoberta e uso de controles químicos de insetos-pragas. Contudo, a contaminação do meio ambiente por pesticidas sintéticos vem aumentando gradativamente devido ao constante uso na tentativa de erradicação de várias pragas e proteção de colheitas agrícolas. ${ }^{1}$ Além disso, as preocupações sobre o potencial impacto dos pesticidas no meio ambiente têm agora tornado mais precisos e mais restritos os procedimentos para registro de novos produtos. ${ }^{2}$ Novos pesticidas, incluindo os com base em produtos naturais, têm sido desenvolvidos para substituir compostos proibidos devido os novos requerimentos de registro. Novos pesticidas são também necessários para combater a evolução da resistência das pragas alvos aos pesticidas..$^{2,3}$

Em virtude da crescente preocupação ambiental quanto à persistência de pesticidas sintéticos e sua potencial toxicidade para humanos, insetos benéficos e animais domésticos, há um renovado interesse no uso de produtos naturais para controle de pragas agrícolas. Inseticidas orgânicos são facilmente produzidos por extração de plantas e apresentam baixa ou nenhuma ação tóxica para humanos. ${ }^{4-6}$

O Nim, Azadirachta indica A. Juss (Meliaceae), planta de origem indiana, é uma fonte promissora de inseticidas orgânicos. Sementes de Nim são fontes de dois tipos de inseticidas naturais: óleo de Nim obtido em prensa mecânica e extratos de média polaridade preparados por maceração em solventes orgânicos. Devido sua relativa seletividade a insetos considerados pragas agrícolas, seus produtos vêm sendo recomendados por diversos programas de manejo integrado de controle de pragas ao redor do mundo..$^{5,7,8}$ Sementes de Nim contêm numerosos metabólitos secundários, sendo o limonoide azadiractina (Azad.) o principal entre outros análogos minoritários que também contribuem para a eficácia global dos extratos. De acordo com o $C R C$ Press Dicitionary of Natural Products pelo menos 237 diferentes compostos foram isolados do gênero Azadirachta. ${ }^{2,9} \mathrm{~A}$ azadiractina é conhecida por ter adversos efeitos em mais de 600 espécies de inseto, a qual tem demonstrado atividade numa faixa de concentração de 1-10 ppm e mais de 500 espécies de insetos são descritos como sensíveis aos extratos de sementes de Nim. ${ }^{4,10}$ Entretanto, estudos com o afídeo

*e-mail: mrforim@ufscar.br
Myzus persicae demonstraram que este desenvolveu rapidamente resistência em formulações preparadas com a azadiractina pura não sendo, todavia, detectada resistência em formulações constituídas com extratos de Nim em mais de 40 gerações. ${ }^{11}$

Produtos naturais como fonte de matéria-prima para a indústria de inseticidas orgânicos podem ser comprometidos pela qualidade do material vegetal utilizado e pelos processos industriais empregados. Vários autores descrevem métodos alternativos de produção de extratos brutos de Nim, que podem ser preparados com conteúdo de até $6 \%$ de azadiractina. ${ }^{8,12}$ Diversos fatores podem exercer influência na constância da produção de metabólitos secundários em uma planta afetando diretamente sua atividade biológica e, consequentemente, a reprodutibilidade da ação inseticida. Fatores como sazonalidade, ritmo circadiano, idade e desenvolvimento vegetal da planta, época, horário e forma de coleta e condições ambientais devem ser considerados para uso do Nim como inseticida natural. ${ }^{13}$ Além disso, condições de armazenamento e procedimentos de preparo dos óleos e extratos certamente afetam a qualidade do produto final. ${ }^{14}$

Assim, um modo de manter a qualidade e garantir a reprodutibilidade da ação inseticida de um produto natural é controlar a qualidade no produto final. Entre as técnicas disponíveis, o enriquecimento de produtos (por exemplo, óleos comerciais de Nim) com extratos orgânicos pode ser realizado facilmente. ${ }^{15,16}$ Todavia, o sucesso na execução do procedimento só é possível através do monitoramento do conteúdo de compostos ativos, como a azadiractina, em cada etapa executada.

O presente trabalho descreve um método de controle de qualidade de óleos e extratos orgânicos de Nim e demonstra a susceptibilidade de Spodoptera frugiperda para estes materiais com diferentes conteúdos do limonoide azadiractina. Para este propósito, primeiramente foi necessário desenvolver uma técnica simples e reprodutiva para preparação de extratos de Nim com elevados teores de azadiractina e procedimentos de controle de qualidade por cromatografia líquida de alta eficiência (CLAE).

\section{PARTE EXPERIMENTAL}

\section{Material vegetal}

Sementes e óleos de Nim foram cedidos pela empresa Baraúna Comercio Indústria Ltda. Os frutos foram lavados, despolpados e 
secos ( 2 dias ao sol e 10 dias a sombra), posteriormente as sementes foram separadas da palha, que foi descartada, finalmente, as sementes foram trituradas num moinho IKA A11 Basic.

\section{Preparação de extratos de Nim}

Diversas técnicas de extração sólido-líquido foram avaliadas visando a máxima eficiência e seletividade, usando como referência o composto azadiractina. Todos os extratos foram preparados em triplicata e analisados por CLAE. As técnicas de extração avaliadas foram:

extração por maceração usando $n$-hexano e etanol (MHE): sementes moídas de Nim $(10,0 \pm 0,1 \mathrm{~g})$ foram maceradas por $60 \mathrm{~min}$ em $100 \mathrm{~mL}$ de $n$-hexano para remoção inicial dos analitos menos polares sendo, após o período de repouso, a solução separada do sólido por filtração. A extração com $n$-hexano foi repetida 5 vezes. O resíduo não extraído foi então macerado com outros $500 \mathrm{~mL}$ de etanol (5 repetições de $100 \mathrm{~mL}$ cada) para extração do analito de interesse. Em cada extração com etanol o material vegetal foi agitado por 5 min e mantido em repouso por $12 \mathrm{~h}$. Todo o etanol foi agrupado;

- extração por maceração usando metanol (MM): sementes moídas de $\operatorname{Nim}(10,0 \pm 0,1 \mathrm{~g})$ foram maceradas com $500 \mathrm{~mL}$ de metanol (5 repetições de $100 \mathrm{~mL}$ ). O material vegetal foi deixado em contato com o solvente, sendo o solvente substituído a cada 12 h;

- $\quad$ extração por maceração usando etanol (ME): os extratos etanólicos foram preparados de maneira similar ao procedimento descrito para extração por maceração usando metanol (MM); extração por maceração usando etanol e agitação constante (MEA): a preparação deste extrato se diferenciou do ME por manter o material vegetal sob agitação mecânica durante todo o período de maceração. Foi utilizado um agitador em hélice Fisatom Mod. 712;

- extração por ultrassom (EU): foram adicionados $50 \mathrm{~mL}$ de etanol em sementes moídas de Nim $(5,0 \pm 0,1 \mathrm{~g})$ para extração dos analitos de interesse sob radiação de ultrassom constante por 10 min; a solução foi separada do sólido por filtração. A extração foi repetida 5 vezes e todo solvente agrupado; - extração por centrifugação (EC): sementes moídas de $\operatorname{Nim}(5,0 \pm 0,1 \mathrm{~g})$ foram centrifugadas com $50 \mathrm{~mL}$ de etanol sob força centrífuga relativa de $10.000 \mathrm{rpm}$ constantes por $10 \mathrm{~min}$. A fase líquida foi separada da sólida e o processo realizado outras 5 vezes. Toda a fase líquida foi agrupada;

- extração por maceração usando agitador de tubos tipo Vortex (MV): foram adicionados $50 \mathrm{~mL}$ de etanol em sementes moídas de Nim $(5,0 \pm 0,1 \mathrm{~g})$ para extração dos analitos de interesse sob agitação constante por $10 \mathrm{~min}$; a solução foi separada do sólido por filtração. A extração foi realizada outras 5 vezes.

A razão entre sementes e solvente foi padronizada em 1 para 10 , respectivamente. Todos os extratos foram obtidos após a evaporação dos solventes de extração em evaporador rotativo sob vácuo.

\section{Desenvolvimento e validação do método cromatográfico}

\section{Padrão de azadiractina}

A azadiractina foi usada como padrão de referência no controle de qualidade dos extratos, correlacionando-se seu teor com a atividade inseticida sobre $S$. frugiperda. O composto azadiractina ( $>95 \%$ pureza) foi extraído de sementes de Nim, purificado por técnicas fitoquímicas clássicas e CLAE semi-preparativa e caracterizado por técnicas espectrométricas no Laboratório de Produtos Naturais do Departamento de Química da UFSCar. ${ }^{17}$

Os espectros de RMN de ${ }^{1} \mathrm{H}(400 \mathrm{MHz})$ e de ${ }^{13} \mathrm{C}(100 \mathrm{MHz})$ em $\mathrm{CD}_{3} \mathrm{OD}$ foram obtidos em espectrômetro Brücker, modelo DRX-400 com um campo de 9,4 T, tendo como referência interna o sinal do TMS.

\section{Materiais e reagentes}

Todos os solventes utilizados foram adquiridos em grau CLAE da Mallinkrodt (Mallinkrodt - St. Louis, MO, USA) e filtrados através de membranas PTFE $(0,45 \mu \mathrm{m})$ da Millipore ${ }^{\circledR}$. A água utilizada nas análises cromatográficas foi purificada usando-se um sistema de purificação Milli-Q (Millipore, Bedford, MA, USA). Todos os solventes foram imersos num banho de ultrassom (Brason 1510R, Danbury, USA) por 15 min antes do uso.

\section{Pré-tratamento}

Os extratos e óleo de Nim foram submetidos à extração em fase sólida para remoção dos interferentes apolares. Cartuchos de ciano (100 mg/1 mL - AccuBond II Agilent Technologies) foram previamente condicionados com $5 \mathrm{~mL}$ de $n$-hexano. Os extratos e óleos (20,0 $\pm 0,5 \mathrm{mg}$ ) foram solubilizados em $n$-hexano $(1 \mathrm{~mL})$ e transferidos para o cartucho. As amostras foram então lavadas com outros $4 \mathrm{~mL}$ de $n$-hexano e posteriormente removidas do cartucho com $1 \mathrm{~mL}$ de metanol. As amostras foram analisadas por CLAE-fase reversa.

\section{Condições cromatográficas}

Cromatógrafo modular Shimadzu (Tóquio, Japão) equipado com bomba LC-10AT $v p$, válvula solenoide FCV-10ALvp, degaseificador DGU-14A, autoinjetor SIL-10AF, detector de ultravioleta SPD-10A $v p$ a $217 \mathrm{~nm}$ e interface SCL-10Avp foi usado em conjunto com uma coluna Phenomenex Luna (II) ${ }^{\circledR} \mathrm{C} 18$ (150 x 4,6 mm, 5 um - Torrance, CA, USA) equipada com coluna de segurança C18 (4 x $3 \mathrm{~mm}$, $5 \mu \mathrm{m})$. As amostras foram injetadas em volumes de $20 \mu \mathrm{L}$. A fase móvel que forneceu melhor seletividade ao método consistia numa mistura isocrática entre acetonitrila/metanol/THF/água (34:4:1:61)

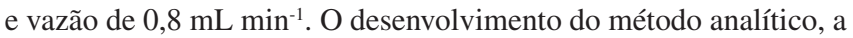
coleção e o processamento dos dados foram otimizados através do software CLASS-VP.

A análise da pureza do padrão de azadiractina via CLAE com espectrometria de massas em sequência (CLAE-EM/EM) foi realizada com um detector do tipo triplo quadrupolo Micromass Quattro LC operado com uma fonte padrão Z-spray adaptada com uma sonda de eletrospray. A ionização foi realizada utilizando o eletrospray no modo negativo de ionização (ESI-). Os parâmetros de separação cromatográfica foram os mesmos já descritos e o detector de massas foi operado nas seguintes condições: potencial do capilar de $2,94 \mathrm{kV}$ para o modo negativo de ionização, temperatura do gás de dessolvatação $\left(\mathrm{N}_{2}\right)$ de $300{ }^{\circ} \mathrm{C}$ e temperatura do bloco da fonte $135^{\circ} \mathrm{C}$. O potencial usado no cone foi de $39 \mathrm{~V}$, no cone extrator de $5 \mathrm{~V}$ e a lente de radio frequência (RF lens) de 0,69 V. Os fluxos dos gases de nebulização $\left(\mathrm{N}_{2}\right)$ e dessolvatação $\left(\mathrm{N}_{2}\right)$ foram de 51 e $350 \mathrm{~L} / \mathrm{h}$, respectivamente. O gás de colisão foi argônio 99,99\% (White Martins) e a voltagem da energia de colisão de $20 \mathrm{eV}$. Os dados totais foram adquiridos usando-se um $d$ well time de $0,06 \mathrm{~s}$. Todos os dados foram processados usando-se o software MassLynx versão 3.5 NT Quattro.

\section{Curva de calibração por padronização externa}

Três curvas de calibração foram requeridas para se obter um grupo de dados necessários ao protocolo estatístico e validação do método. A curva de calibração foi obtida por análise de regressão (modelo linear) interpolando a concentração nominal dos padrões usados com a área do pico cromatográfico obtida usando-se o software Origin 5.0 Professional. A análise estatística dos dados e os cálculos de retorno foram realizados pelo software Microsoft Office Excel 2003.

A solução estoque de azadiractina foi preparada diluindo-se $10 \mathrm{mg}$ 
do padrão em $10 \mathrm{~mL}$ de metanol. A solução foi armazenada em frasco âmbar a $-20^{\circ} \mathrm{C}$. Soluções filhas foram preparadas após a evaporação em Speed Vac (43 ${ }^{\circ} \mathrm{C}, 20$ min.) de 25, 50, 100, 200, 300, 400, 500 e $600 \mu \mathrm{L}$ da solução estoque e reconstituídas com $1,0 \mathrm{~mL}$ de metanol. As concentrações intermediárias preparadas foram 50, 100, 200, 300, 400,500 e $600 \mu \mathrm{g} \mathrm{mL}^{-1}$, respectivamente. As soluções utilizadas na construção da curva de calibração foram preparadas secando-se $20 \mu \mathrm{L}$ de cada solução filha e submetidas ao mesmo pré-tratamento descrito no preparo de amostras por extração em fase sólida. Entretanto, após serem removidas do cartucho as amostras foram novamente secas e reconstituídas com 0,2 mL de metanol. As concentrações finais das amostras preparadas para construção da curva de calibração foram 5,0; 10,0; 20,0; 30,0; 40,0; 50,0 e 60,0 $\mu \mathrm{g} \mathrm{mL}^{-1}$.

\section{Precisão e exatidão}

A precisão e exatidão do método foram determinadas usando-se soluções de azadiractina em 6,0; 25,0 e 54,0 $\mu \mathrm{g} \mathrm{mL} \mathrm{m}^{-1}$. Estes valores foram selecionados por possuírem concentrações dentro da faixa linear de trabalho utilizada $\left(5,0\right.$ a $\left.60,0 \mu \mathrm{g} \mathrm{mL}^{-1}\right)$. Elas foram usadas para se investigar a variabilidade no método para análises intra e interdias. Para cada concentração foram preparadas 5 amostras analisadas em 3 dias diferentes não consecutivos.

\section{Limite de detecção e quantificação}

O limite de detecção foi calculado como sendo LQ = Desvio padrão do intercepto x 3,33 / coeficiente angular da reta e o Limite de quantificação como LQ = Desvio padrão do intercepto x 10 / coeficiente angular da reta.

\section{Atividade biológica dos extratos de Nim sobre Spodoptera frugiperda}

Para se obter um fator de comparação como o extrato MHE, os extratos MM, ME, MEA, EU, EC e MV foram particionados entre hexano e metanol/água para a remoção do óleo. Os extratos hidroalcoólicos foram concentrados e secos.

Os ensaios biológicos foram realizados no Laboratório de Bioensaios do Departamento de Química da UFSCar, mantido a $25 \pm$ $1{ }^{\circ} \mathrm{C}$, UR de $70 \pm 5 \%$ e fotofase de $12 \mathrm{~h}$. Para realização dos testes, foi usada uma criação de $S$. frugiperda mantida em laboratório, com lagartas alimentadas por dieta artificial. ${ }^{18,19}$

Para a realização dos bioensaios, após a solubilização em etanol, as amostras foram secas e posteriormente incorporadas à dieta artificial para $S$. frugiperda na proporção de 100,250 e $1.000 \mathrm{mg}$ de extrato de Nim para $1000 \mathrm{~g}$ de dieta $\left(\mathrm{mg} \mathrm{kg}^{-1}\right)$, com o cuidado de adicioná-lo ao final, quando a dieta estava a uma temperatura de 50 ${ }^{\circ} \mathrm{C}$. Além das dietas correspondentes a cada tratamento, também foi preparada uma dieta testemunha, sem extrato, utilizando-se o solvente em que foram solubilizados os extratos. ${ }^{18,20}$

Depois da preparação, as dietas foram vertidas em tubos de vidro $(8,5 \times 2,5 \mathrm{~cm})$, previamente esterilizados, em estufa a $170{ }^{\circ} \mathrm{C}$ por $1 \mathrm{~h}$ e, em seguida, tampados com algodão hidrófugo. Após a colocação da dieta, os tubos foram mantidos por $24 \mathrm{~h}$ em grades de arame para eliminação do excesso de umidade (gotículas de água) de suas paredes. Na sequência foi feita a inoculação das lagartas recém-eclodidas de $S$. frugiperda, utilizando-se uma lagarta por tubo de vidro. Para cada extrato foram utilizadas 40 lagartas, distribuídas em quatro repetições de 10 lagartas cada, em delineamento completamente casualizado.

\section{RESULTADOS E DISCUSSÃO}

O sucesso de uma análise quantitativa está diretamente ligado à qualidade e especificações do padrão de referência usado no processo.
Não foi encontrado um padrão de qualidade disponível comercialmente. Assim, tornou-se necessário o trabalho de extração, isolamento e caracterização deste analito. Na Figura 1A pode ser observado o cromatograma do padrão azadiractina. A análise do pico cromatográfico da azadiractina num detector de arranjo de diodos apresentou um comprimento de onda com máxima absorção em 217 nm e 100\% de pureza cromatográfica.

Azadiractina possui a fórmula molecular $\mathrm{C}_{35} \mathrm{H}_{44} \mathrm{O}_{16}$. O pico cromatográfico ilustrado na Figura 1 foi confirmado como referente à azadiractina por cromatografia líquida acoplada a espectrômetro de massas em sequência (CLAE-EM/EM) usando-se uma fonte eletrospray no modo negativo de ionização $\left(\mathrm{ESI}^{-}\right)$. A varredura na amostra foi composta, basicamente, pelo pseudo-íon molecular $\left([\mathrm{M}-\mathrm{H}]^{-}\right)$ 719 Da e dos íons filhos $m / z$ 687, 659, 641 e 535.
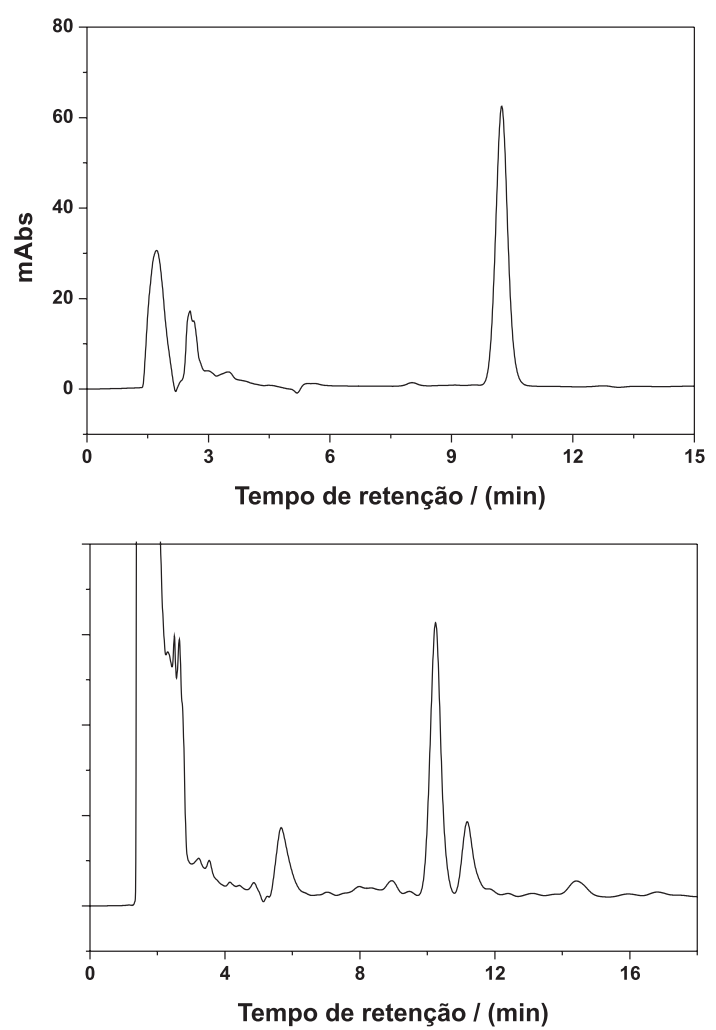

Figura 1. Cromatograma do padrão de azadiractina (A) e de extratos de Nim (B). Condições cromatográficas: coluna Phenomenex Luna $(\text { II })^{\circledR}$ C18 $(150 x$ 4,6 mm, 5 um - Torrance, CA, USA) equipada com coluna de segurança C18 (4 $x 3 \mathrm{~mm}, 5 \mu \mathrm{m})$, eluição isocrática com fase móvel quaternária de acetonitrila/ metanol/THF/água (34:4:1:61) e vazão de 0,8 $\mathrm{mL} \mathrm{min} \mathrm{m}^{-1}$ e comprimento de onda selecionado de $217 \mathrm{~nm}$

A caracterização final do padrão foi realizada por ressonância magnética nuclear ${ }^{1} \mathrm{H} \mathrm{e}{ }^{13} \mathrm{C}$. O composto apresentou sinais de hidrogênios $\delta=4,76(m, \mathrm{H}-1)$; 2,32 ( $m, \mathrm{H}-2 \mathrm{a}) ; 2,26(t l, 3,3 \mathrm{~Hz}, \mathrm{H}-2 \mathrm{~b})$; $5,50(t l, 2,8 \mathrm{~Hz}, \mathrm{H}-3) ; 3,35$ (d, 12,5 Hz, H-5); 4,61 (dd, 12,5; 2,7 Hz, H-6); 4,76 (m, H-7); 3,34 (m, H-9); 4,67 (dl, 3,3 Hz, H-15); 1,68 (m, H-16a); 1,32 (d, 13,1 Hz, H-16b); 2,38 (dl, 5,2 Hz, H-17); 2,01 ( $s l$, H-18); 4,15 (d, 9,7 Hz, H-19a); 3,63 (d, 9,7 Hz, H-19b); 5,65 ( $s l$, H-21); 5,05 (d, 2,9 Hz, H-22); 6,46 (d, 2,9 Hz, H-23); 4,08 (d, 8,9 $\mathrm{Hz}, \mathrm{H}-28 \mathrm{a}) ; 3,77$ ( $d, 8,9 \mathrm{~Hz}, \mathrm{H}-28 \mathrm{~b}) ; 1,75$ ( $s, \mathrm{H}-30) ; 2,87$ ( $s, \mathrm{OH}-7)$; $5,04$ ( $s, \mathrm{OH}-11)$; 2,94 ( $s, \mathrm{OH}-20)$; 3,69 ( $s, \mathrm{OMe}-12)$; 3,80 ( $s, \mathrm{OMe}-$ 29); 1,95 ( $s$, OAc-3); 6,95 ( $m, \mathrm{H}-3$ '); 1,78 ( $d d, 7,1$; 0,8 Hz, H-4') e 1,85 ( $m, \mathrm{H}-5$ '). O espectro de $\mathrm{RMN}^{13} \mathrm{C}$ apresentou sinais $\delta=70,5$ (CH-1); 29,7 (CH2-2); 66,9 (CH-3); 52,5 (C-4); 37,0 (CH-5); 73,7 (CH-6); 74,7 (CH-7); 45,3 (C-8); 44,6 (CH-9); 50,0 (C-10); 104,1 
(C-11); 171,8 (C-12); 68,5 (C-13); 69,9 (C-14); 76,4 (CH-15); 24,9 (CH2-16); 48,6 (CH-17); 18,3 (CH3-18); 69,1 ( $\left.\mathrm{CH}_{2}-19\right) ; 83,1$ (C20); 108,8 (CH-21); 107,3 (CH-22); 147,1 (CH-23); 73,0 ( $\left.\mathrm{CH}_{2}-28\right)$; 173,3 (C-29); 21,3 (C-30); 53,3 ( $\left.\mathrm{OCH}_{3}-12\right) ; 52,7\left(\mathrm{OCH}_{3}-29\right) ; 169,6$ e 20,9 $\left(\mathrm{OCOCH}_{3}-3\right)$; 166,2 (C-1'); 128,6 (C-2'); 137,8 (C-3'); 14,3 (C-4') e 11,9 (C-5').

Estes dados em comparação com os apresentados na literatura confirmam o composto azadiractina e sua pureza, podendo ser usado como padrão de referência. ${ }^{21}$

\section{Validação do método}

A linearidade foi investigada para toda a faixa dinâmica de trabalho. As curvas de calibração foram construídas utilizando-se a área do pico cromatográfico do padrão versus a quantidade de azadiractina adicionada. Linearidade satisfatória foi obtida entre 5,0 e 60,0 $\mu \mathrm{g}$ $\mathrm{mL}^{-1}$. A curva de calibração média, construída através da intersecção da área dos padrões e a concentração nominal, pode ser observada na Figura 2A. O procedimento de ajuste da reta foi realizado pelo método de regressão linear. A equação de reta determinada foi $y=$ $18.717,3 x+465,4$ e coeficiente de correlação $r^{2}=0,9997$.
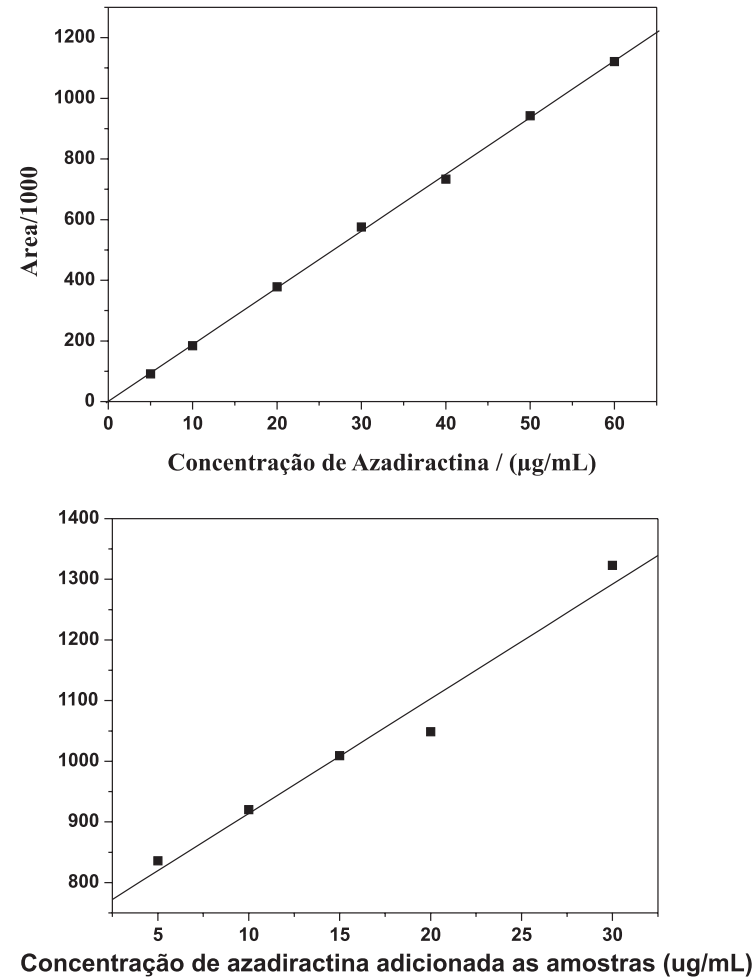

Figura 2. Curva de calibração externa (A) e curva de adição de padrão para azadiractina $(B)$

A exatidão e precisão do método analítico foram investigadas preparando-se padrões em três níveis de concentrações diferentes abrangendo toda a faixa dinâmica de trabalho. Na determinação da precisão [Desvio padrão relativo $-\operatorname{DPR}(\%)=($ desvio padrão/média $)$ x 100\%; $n=15$ ] e da exatidão [Exatidão = (medida da concentração/ concentração nominal) x $100 \%, n=15$ ] o erro obtido foi menor que $2 \%$ considerando-se a área de cada concentração investigada. Para determinação da precisão e exatidão intra e interdias, cada ponto foi analisado em quintuplicata em 3 dias não consecutivos.

O método mostrou-se seletivo podendo distinguir a resposta do analito de interesse dos demais componentes da amostra. A seletividade foi estabelecida fazendo-se uso do detector de ultravioleta, foto-diodo (operado na região do UV/Vis) e espectrômetro de massas em sequência. Foi calculado para a azadiractina e 3-tigloilazadirachtol o fator de retenção, $k$, de 4,6 e 5,1, respectivamente. $\mathrm{O}$ fator de separação $(\alpha)$ e de retenção $\left(\mathrm{R}_{\mathrm{s}}\right)$ determinados foram 1,10 e 1,90, respectivamente. A separação cromatográfica pode ser observada na Figura 1B.

A seletividade também foi avaliada juntamente com a recuperação do método através da construção de uma curva de calibração por padronização externa e outra por adição de padrão (Figura 2).

O método de adição de padrão consistiu na adição de quantidades conhecidas do composto de interesse $(50 \mu \mathrm{L})$ de soluções em diferentes concentrações: 50,0; 100,0; 150,0; 200,0 e 300,0 $\mu \mathrm{g} \mathrm{mL} \mathrm{m}^{-1}$ sobre uma quantidade fixa de sementes de Nim trituradas $(25 \mathrm{mg}$ ). Depois de homogeneizar a solução na matriz, todas as amostras foram secas e extraídas com metanol por centrifugação. Os extratos obtidos foram submetidos aos mesmos procedimentos de pré-tratamento e análises descritos para as amostras. Após serem removidas do cartucho na etapa de pré-tratamento, as amostras foram secas e reconstituídas com $0,5 \mathrm{~mL}$ de metanol. As concentrações finais dos padrões utilizados na construção da curva de calibração foram 5,0;10,0;15,0;20,0 e 30,0 $\mu \mathrm{g} \mathrm{mL}^{-1}$.

A curva da calibração de padronização por adição de padrão foi usada para determinar a recuperação do método, permitindo avaliar o efeito da matriz para diferentes concentrações do analito em investigação. Possíveis interferências da matriz durante o pré-tratamento ou perda de seletividade no método produziriam uma modificação na inclinação da reta. $\mathrm{O}$ coeficiente de inclinação $(a)$ obtido para as curvas de calibração por padronização externa e adição de padrão foram $18.717,3$ e $18.901,8$, respectivamente, com uma aproximação superior a $99 \%$. Este resultado demonstra a inexistência de interferência da matriz, quando submetida ao pré-tratamento por extração em fase sólida, na quantificação do conteúdo de azadiractina para as amostras investigadas.

O limite de quantificação do método foi calculado em $3,8 \mu \mathrm{g} \mathrm{mL} \mathrm{L}^{-1}$ e o limite de detecção em $1,3 \mu \mathrm{g} \mathrm{mL} \mathrm{m}^{-1}$.

\section{Ação inseticida do Nim}

A eficácia de um inseticida natural como o Nim está diretamente relacionada com a avaliação da qualidade do produto desenvolvido. Fatores como sazonalidade, genética, condições ambientais etc. não podem ser controlados para cultivos em grande escala. Extratos produzidos com sementes coletadas no mesmo período em Juazeiro - BA, Petrolina - PE e Catanduva - SP apresentaram conteúdos de azadiractina de 61.698,0, 58.094,0 e 46.403,7 $\mathrm{mg} \mathrm{kg}^{-1}$, respectivamente.

A reprodutibilidade dos resultados em campo e maior eficácia do Nim podem ser obtidas através do uso de quantidades específicas de extratos produzidos em função do conteúdo do princípio ativo quantificado. Dependendo da forma de emprego, os extratos de Nim também podem ser usados no enriquecimento do óleo de Nim, forma mais comum de uso, para valores específicos e reprodutivos. Os extratos alcoólicos podem ser incorporados ao óleo em quantidades específicas corrigindo-se, por exemplo, o conteúdo de azadiractina no produto final decorrente de variações sazonais, mantendo a reprodutibilidade dos lotes e eficácia do produto final. A Figura 3 mostra os cromatogramas de análises de óleos de Nim enriquecidos com extratos com conteúdo reprodutíveis de azadiractina para 1.000, 2.000 e $4.000 \mathrm{mg} \mathrm{kg}^{-1}$.

A técnica de enriquecimento é um processo simples que consiste em incorporar ao óleo de Nim quantidades conhecidas de extratos, elevando o teor de azadiractina a valores específicos e reprodutivos, garantindo a homogeneidade e reprodutibilidade do produto final no controle de pragas. ${ }^{15}$ Todavia, tal desenvolvimento e sua avaliação só são permitidos através do uso de ferramentas de controle de qualidade como a cromatografia líquida de alta eficiência. 


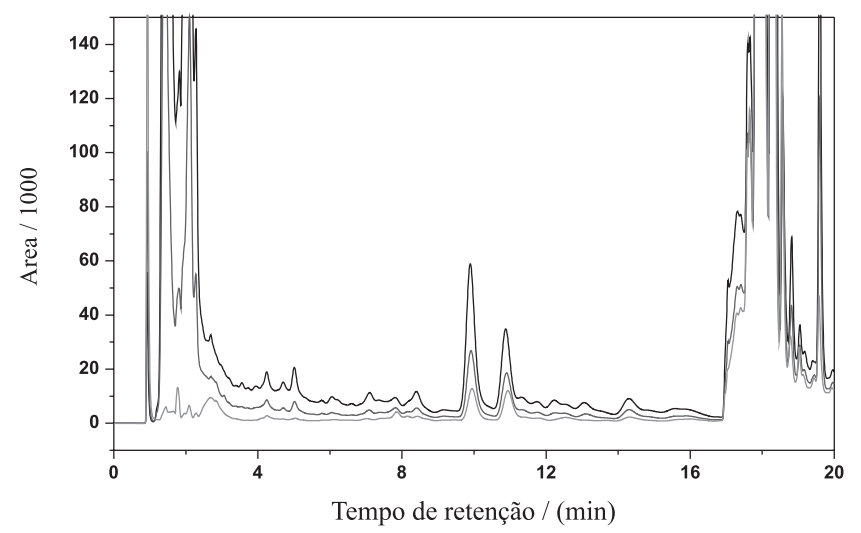

Figura 3. Cromatogramas de óleos de Nim com 1.000, 2.000 e $4.000 \mathrm{mg} \mathrm{kg}^{-1}$. CLAE operado conforme parâmetros descritos na Figura 1

A análise cromatográfica dos extratos preparados permitiu determinar a quantidade de azadiractina em cada um deles (Tabela 1). A análise das sementes usadas no preparo dos extratos revelou um conteúdo de azadiractina de $2.348,5 \mathrm{mg} \mathrm{kg}^{-1}$. Assim, conhecendo o rendimento de cada extrato e comparando os resultados quantitativos obtidos com o resultado da análise da semente se determinou a eficiência de extração dos métodos investigados.

Entre os métodos analisados os que apresentaram melhor eficiência foram os MHE (fração etanólica) (100,1\%), ME (100,1\%) e MEA $(99,1 \%)$ onde foram usados etanol. Os resultados obtidos com as extrações ME e MEA descartam a necessidade de uma extração inicial com $n$-hexano. Portanto, os métodos ME e MEA indicam economia e vantagem em relação ao custo e ao meio ambiente. Contudo, estes extratos não se apresentaram homogêneos devido à presença de óleo de Nim, parcialmente extraído pelo etanol, enquanto no método de extração $a$, obteve-se um extrato seco e homogêneo. Assim, o método MHE é indicado para o preparo de extratos sólidos sem a necessidade futura de técnicas de fracionamento e separação. $\mathrm{O}$ uso deste extrato seco em formulações apresenta vantagens em relação ao uso da planta em pó, tais como uma maior concentração de princípios ativos, a possibilidade de padronização do conteúdo, melhorar a biodisponibilidade e menor contaminação microbiana.

A importância do controle de qualidade sobre a reprodutibilidade da ação de um inseticida natural como o Nim foi investigada através de ensaios utilizando como alvo $S$. frugiperda. Após serem particionados para remoção do óleo, cada extrato foi ensaiado nas concentrações de 100,250 e $1000 \mathrm{mg}$ de extrato para $1000 \mathrm{~g}$ de dieta. Os novos teores de azadiractina ensaiados, obtidos após a partição, também podem ser observados na Tabela 1 .

Tabela 1. Teor de azadiractina (Aza.) nos extratos de Nim e nas amostras ensaiadas em $S$. frugiperda após serem particionadas

\begin{tabular}{lcccc}
\hline Extrato & $\begin{array}{c}\text { Teor de Aza** } \\
\left(\mathrm{mg} \mathrm{kg}^{-1} \text { extrato }\right)\end{array}$ & $\begin{array}{c}\text { Teor calculado de } \\
\text { Aza. nas semente } \\
\left(\mathrm{mg} \mathrm{kg}^{-1}\right)\end{array}$ & $\begin{array}{c}\text { Eficiência de } \\
\text { extração }(\%)\end{array}$ & $\begin{array}{c}\text { Teor de Aza. } \\
\text { amostras } \\
\text { particionadas } \\
\left(\mathrm{mg} \mathrm{kg}^{-1}\right)\end{array}$ \\
\hline MHE & $32.480,3$ & $2.351,2$ & 100,1 & $32.480,3$ \\
MM & $4.094,3$ & $1.274,8$ & 54,3 & $12.070,8$ \\
ME & $2.633,5$ & $2.350,5$ & 100,1 & $21.046,9$ \\
MEA & $3.311,4$ & $2.328,1$ & 99,1 & $19.534,8$ \\
EU & $1.542,6$ & $1.330,2$ & 56,6 & $29.464,6$ \\
EC & $1.719,9$ & $1.058,1$ & 45,1 & $1.385,0$ \\
MV & $2.267,8$ & $1.361,6$ & 58,0 & $18.459,2$ \\
\hline
\end{tabular}

* Os coeficientes de variação entre quantidade de extrato obtido e análise cromatográfica (triplicatas) foram inferiores a 5 e $12 \%$, respectivamente.
Os extratos que foram incorporados à dieta artificial numa concentração de $100 \mathrm{mg} \mathrm{kg}^{-1}$ de dieta demonstraram uma tendência em alongar a fase larval em 10,1 dias para as lagartas alimentadas com a dieta tratada com o extrato EU a $100 \mathrm{mg} \mathrm{kg}^{-1}$, em relação ao controle (Tabela 2). O extrato MHE apresentou $100 \%$ de mortalidade e o extrato EC não se mostrou eficiente nesta concentração. Uma maior duração da fase larval, em campo, deixará o inseto por mais tempo propenso ao ataque de parasitoides, predadores e entomopatógenos, provocando ainda maior competição pelo alimento. Os adultos que emergirão desses indivíduos terão assincronia com a população normal e, consequentemente, a cópula será dificultada ou quando existir tenderá à consanguinidade pelo acasalamento de indivíduos da mesma geração. Também será diminuído o número de gerações do inseto no ciclo agrícola. ${ }^{22}$

Tabela 2. Médias da duração (dias) das fases larval e pupal, mortalidade (\%) da fase larval e médias do peso pupal (mg) de Spodoptera frugiperda alimentadas com dieta artificial tratadas com os extratos de $A$. inidica em concentração de $100 \mathrm{mg} \mathrm{kg}^{-1}$

\begin{tabular}{lcccc}
\hline $\begin{array}{l}\text { Concentração } \\
100 \mathrm{mg} / \mathrm{kg}\end{array}$ & $\begin{array}{c}\text { Fase Larval } \\
\text { Duração (dias) }\end{array}$ & $\begin{array}{c}\text { Fase Pupal } \\
\text { Duração (dias) }\end{array}$ & $\begin{array}{c}\text { Peso Pupal } \\
(\mathrm{mg})\end{array}$ & $\begin{array}{c}\text { Fase Larval } \\
\text { Mortalidade }(\%)\end{array}$ \\
\hline EU & 27,67 & 11,50 & 171,67 & 70,00 \\
MV & 17,80 & 11,00 & 251,60 & 60,00 \\
MEA & 19,12 & 10,62 & 217,12 & 20,00 \\
ME & 15,89 & 10,11 & 276,78 & 10,00 \\
MM & 16,10 & 10,00 & 267,90 & 10,00 \\
Controle & 17,56 & 9,56 & 267,89 & 10,00 \\
\hline
\end{tabular}

Temperatura: $25 \pm 2{ }^{\circ} \mathrm{C}$; UR: $70 \pm 5 \%$; Fotofase de $12 \mathrm{~h}$.

O prolongamento da fase larval relaciona-se geralmente com o crescimento mais lento e pouca ingestão de alimento, por existir neste um ou vários aleloquímicos tóxicos ou por ocorrer desbalanço nutricional. Em campo, o crescimento lento das lagartas levará a um menor consumo de alimento, ocasionando menor dano nas plantas. ${ }^{22}$ Além da tendência em alongar a fase larval, as lagartas criadas com a dieta artificial tratada com o extrato EU a $100 \mathrm{mg} \mathrm{kg}^{-1}$ apresentaram uma diminuição do peso pupal de aproximadamente $96,2 \mathrm{mg}$. Menor peso de pupas indica menor consumo de alimento ou menor eficiência de conversão do alimento ingerido, possivelmente devido à presença de deterrentes ou ausência de fagoestimulantes. ${ }^{23} \mathrm{O}$ prolongamento do período de desenvolvimento e a diminuição do peso das pupas nos indivíduos sobreviventes neste trabalho indicam que, além de inibir o crescimento larval, é possível que também tenha ocorrido inibição na alimentação ou menor eficiência de conversão do alimento ingerido, o que, segundo Tanzubil e Mccaffery, ocorre quando os insetos são sujeitos a altas doses de substância tóxica. ${ }^{22}$ Além disso, a duração da fase larval e o peso das lagartas apresentarem as mesmas tendências é um fato que ocorre frequentemente nos estudos de biologia de insetos. ${ }^{24}$

Analisando a Figura 4, observa-se que somente as lagartas alimentadas com a dieta artificial tratada com o extrato MHE (100,0 $\mathrm{mg} \mathrm{kg}^{-1}$ ) apresentaram $100 \%$ de taxa de mortalidade larval, seguido pelo extrato EU que apresentou taxa de mortalidade larval de $70 \%$.

Nestes resultados se observa que a taxa de mortalidade larval é diretamente proporcional ao conteúdo de azadiractina no extrato usado. Tais resultados confirmam a necessidade de controle sobre o conteúdo de azadiractina, garantindo a reprodutibilidade da ação inseticida desejada nos produtos a serem comercializados.

As amostras ensaiadas com $250 \mathrm{mg}$ de extrato em $1000 \mathrm{~g}$ de dieta novamente demonstram a relação entre conteúdo de azadiractina e ação inseticida. Ao aumentar a dosagem, melhorou a taxa de mortalidade. Pode-se observar na Figura 4 que o extrato menos ativo foi o EC, o qual apresentou menor conteúdo de azadiractina (Tabela 3) na dieta. Observa-se que praticamente todas as dietas que continham um 


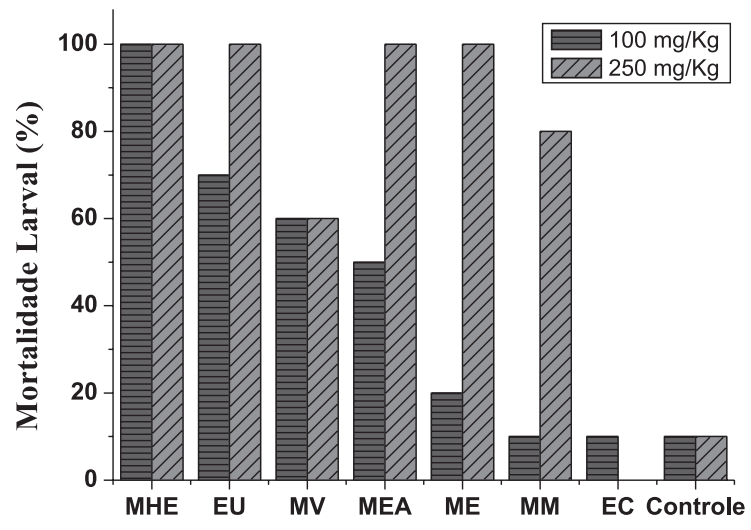

Figura 4. Médias da mortalidade da fase larval (\%) de lagartas de S. frugiperda alimentadas com dieta artificial tratadas com extratos de A. indica a 100,0 e 250,0 $\mathrm{mg} \mathrm{kg}^{-1}$

Tabela 3. Teor de azadiractina presente na dieta administrada à S. frugiperda

\begin{tabular}{lccc}
\hline Extrato & \multicolumn{3}{c}{ Teor de Azadiractina $\left(\mathrm{mg} \mathrm{kg}^{-1}\right)$} \\
& $\begin{array}{r}100 \mathrm{mg} \mathrm{kg}^{-1} \backslash \\
\text { (Extrato/Dieta) }\end{array}$ & $\begin{array}{c}250 \mathrm{mg} \mathrm{k}^{-1} \backslash \\
\text { (Extrato/Dieta) }\end{array}$ & $\begin{array}{c}1.000 \mathrm{mg} \mathrm{kg}^{-1} \\
\text { (Extrato/Dieta) }\end{array}$ \\
\hline MHE & 3,2 & 8,1 & 32,5 \\
MM & 1,2 & 3,0 & 12,1 \\
ME & 2,1 & 5,3 & 21,0 \\
MEA & 2,0 & 4,9 & 19,5 \\
EU & 2,9 & 7,4 & 29,5 \\
EC & 0,1 & 0,3 & 1,4 \\
MV & 1,8 & 4,6 & 18,5 \\
\hline
\end{tabular}

teor de azadiractina superior a $3,0 \mu \mathrm{g} \mathrm{kg}^{-1}$ de dieta causaram $100 \%$ de mortalidade.

Ao se incorporar os extratos de Nim à dieta artificial para $S$. frugiperda a $1.000 \mathrm{mg} \mathrm{kg}^{-1}$, todos os extratos ensaiados apresentaram aproximadamente $100 \%$ de taxa de mortalidade larval. O extrato EC, com $1,4 \mu \mathrm{g} \mathrm{kg}^{-1}$ de azadiractina na dieta apresentou $90 \%$ de mortalidade somente após 15 dias.

\section{CONCLUSÕES}

Os principais produtos de Nim comercializados são óleos e extratos. O controle de qualidade destes produtos pode ser realizado por diversas técnicas cromatográficas. O método desenvolvido e validado utilizando CLAE-UV demonstrou elevada seletividade e sensibilidade para a azadiractina. O método mostrou-se reprodutivo podendo ser aplicado nas análises de sementes, extratos e óleos de Nim possibilitando o aprimoramento da qualidade dos produtos e reprodutibilidade da ação inseticida. O conhecimento do teor de azadiractina presente nos extratos ensaiados sobre a $S$. frugiperda permitiu estipular uma concentração mínima de azadiractina igual a $3,0 \mu \mathrm{g} \mathrm{kg}^{-1}$ de dieta para obter $100 \%$ de mortalidade.

\section{AGRADECIMENTOS}

À Fundação de Amparo à Pesquisa do Estado de São Paulo (FAPESP) pelo apoio financeiro e ao Sr. R. A. Malimpence por fornecer óleos e sementes de Nim.

\section{REFERÊNCIAS}

1. Matsumura, F., ed., Toxicology of Insecticides, Plenum: New York, 1975; Tanabe, S., Hidaka, H.; Tatsukawa, R.; Chemosphere 1983, 12, 277; Scheyer, A.; Graeff, C.; Morville, S.; Mirabel, P.; Millet, M.; Chemosphere 2005, 58, 1517.

2. Dayan, F. E.; Cantrell, C. L.; Duke, S. O.; Bioorg. Med. Chem. 2009, 17, 4022.

3. Copping, L. G.; Duke, S. O.; Pest Manage. Sci. 2007, 63, 524.

4. Nathan, S. S.; Kalaivani, K.; Sehoon, K.; Murugan, K.; Chemosphere 2006, 62, 1381.

5. Nathan, S. S.; Kalaivani, K.; Murugan, K.; Chung, P. G.; Pestic. Biochem. Physiol. 2005, 81, 113.

6. Youn, Y. N.; Seo, M. J.; Shin, J. G.; Jang, C.; Yu, Y. M.; Biological Control 2003, 28, 164; Covaci, A.; Gheorghe, A.; Schepens, P.; Chemosphere 2004, 56, 757.

7. Nathan, S. S.; Kalaivani, K.; Murugan, K.; Chung, P. G.; Crop Prot. 2005, 24, 760; Nathan, S. S.; Chung, P. G.; Murugan, K.; Phytoparasitica 2004, 32, 433; Ishida, M.; Serit, M.; Nakata, K.; Juneja, L. R.; Kim, M.; Takahashi, S.; Biosci., Biotechnol., Biochem. 1992, 56, 1835.

8. Schmutterer, H.; Annu. Rev. Entomol. 1990, 35, 271.

9. Butterworth, J. H.; Morgan, E. D.; Chem. Commun. 1968, 1, 23.

10. Morgan, E. D.; Bioorg. Med. Chem. 2009, 17, 4096; Govindachari, T. R.; Gopalakrishnan, G.; J. Indian Chem. Soc. 1998, 75, 655; Mordue, A. J.; Blackwell, A.; J. Insect Physiol. 1993, 39, 903; Martinez, S. S.; O Nim - Azadirachta indica. Natureza, usos múltiplos, produção, IAPAR: Londrina, 2002.

11. Feng, R.; Isman, M. B.; Experientia 1995, 51, 831.

12. Sharma, V.; Walia, S.; Kumar, J.; Nair, M. G.; Parmar, B. S.; J. Agric. Food Chem. 2003, 51, 3966; Ambrosino, P.; Fresa, R.; Fogliano, V.; Monti. S. M.; Ritieni, A.; J. Agric. Food Chem. 1999, 47, 5252; Dai, J.; Yaylayan, V. A.; Raghavan, G. S. V.; Parè, J. R.; J. Agric. Food Chem. 1999, 47, 3738; Shidu, O. P.; Behl, H. M.; Curr. Sci. 1996, 70, 1084.

13. Lindroth, R. L.; Hsia, M. T. S.; Scriber, J. M.; Biochem. Syst. Ecol. 1987, 15, 681; Darrow, K.; Bowers, M. D.; Biochem. Syst. Ecol. 1997, 25, 1; Hartmann, T.; Ent. Exp. Appl. 1996, 80, 177; Kutchan, T. M.; Plant Physiol. 2001, 125, 58; Gobbo-Neto, L.; Lopes, N. P.; Quim. Nova 2007, 30, 374.

14. Shidu, O. P.; Kumar, V.; Behl, H. M.; J. Agric. Food Chem. 2003, 51, 910.

15. Forster, P.; Mose, G.; Status report on global Neem surge, GTZ: Eschborn, 2000.

16. Gesellschaft, D.; Proceedings of a Seminar Held in Dodowa, Eschborn: October 1998.

17. Jarvis, A. P.; Morgan, E. D.; Edwards, C.; Phytochem. Anal. 1999, 10, 39; Schroeder, D. R.; Nakanishi, K.; J. Nat. Prod. 1987, 50, 241.

18. Kasten, P. J. R.; Precetti, A. A. C. M.; Parra, J. R. P.; Rev. Agric. 1978, 53,68 .

19. Parra, J. R. P. Em Criação de insetos para estudos com patógenos; Alves, S. B., ed.; Ed. Manole: São Paulo,1986.

20. Leite, A. C.; Matos, A. P.; Batista-Pereira, L. G.; Fernandes, J. B.; Vieira, P. C.; Da Silva, M. F. G. F.; Biopest. Int. 2008, 4, 28.

21. Barrek, S.; Paisse, O.; Grenier-Loustalot, M-F.; Anal. Bioanal. Chem. 2004, 378, 753; Denholm, A. A.; Jennens, L.; Ley, S. V.; Wood, A.; Tetrahedron 1995, 51, 6591; Kraus, W.; Bokel, M.; Bruhn, A.; Cramer, R.; Klaiber, I.; Klenk, A.; Nagl, G.; Pöhnl, H.; Sadlo, H.; Vogler, B.; Tetrahedron 1987, 43, 2817.

22. Tanzubil, P. B.; McCaferry, A. R.; Crop Prot. 1990, 9, 383.

23. Rodríguez, H. C.; Vendramim, J. D.; Rev. Agric. 1997, 72, 305.

24. Bogorni, P. C.; Vendramin, J. D.; Neotrop. Entomol. 2005, 34, 311. 